\title{
COMO ACONTECE A INOVAÇÃO NO MERCADO DE ELETROPORTÁTEIS: UM ESTUDO DE CASO RELACIONADO À MARCA CADENCE.
}

\section{AS INNOVATION IN APPLIANCES MARKET: A CASE STUDY RELATED TO THE BRAND CADENCE.}

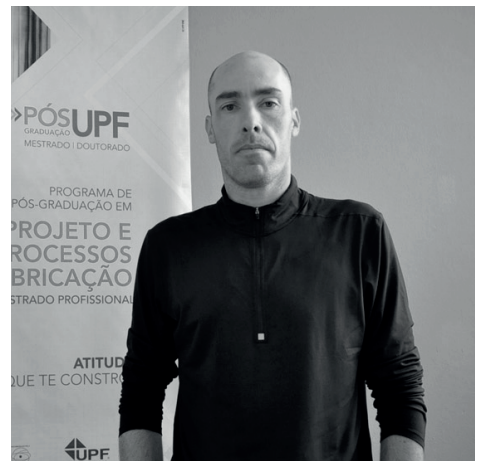

\author{
Márcio Walber \\ Professor/Coordenador do Programa de Pós-graduação \\ em Projeto e Processos de Fabricação - UPF _ \\ Universidade de Passo Fundo \\ Doutor em Engenharia Mecânica
}

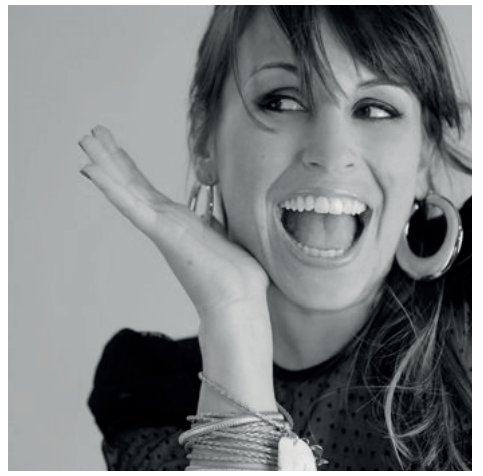

\section{Fernanda Flach Pandolfo} Designer da Cadence S.A.

Especialista em Gestão Estratégica do Design - UNIVALI fernandinhadesign@gmail.com

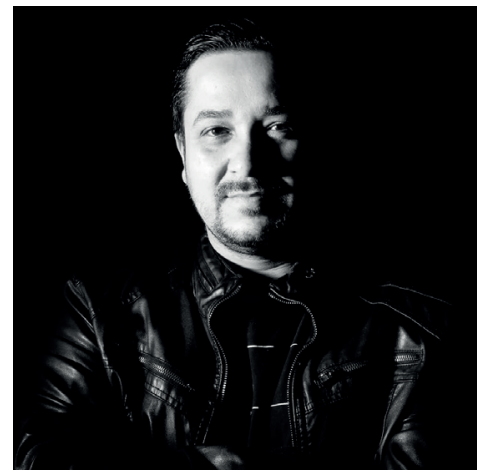

\section{Carlos Davi Matiuzzi da Silva}

Especialista em Design Gráfico e Mídias - UPF Universidade de Passo Fundo Mestre em Projeto e Processos de Fabricação - UPF Universidade de Passo Fundo davicrz@gmail.com 


\section{RESUMO}

No mercado de eletroportáteis brasileiro, percebe-se que poucas marcas tem sua cultura empresarial voltada à inovação. Objetiva-se deste modo, investigar o processo de inovação dentro de uma idústria de eletrodomésticos. $O$ alinhamento das tendências de design com o comportamento do consumidor traz inspiração para diferenciar-se dos produtos oferecidos pela concorrência. A Cadence, marca brasileira que iniciou sua trajetória importando eletroportáteis da China, sentiu a necessidade de inovar e incorporar o design em seu DNA. Através de um estudo de caso e de um processo de investigação in-loco foi possível identificar o pensamento de inovação e design da linha Colors lançada pela empresa em 2013, desta forma identificou-se que processo de inovação baseou-se na experiência de uso para o desenho das formas e tendências de cor para o segmento, desta forma o produto passou a integrar-se ao seu ambiente de uso como um item também decorativo.

\section{PALAVRAS-CHAVE}

Eletroportáteis, Inovação, Design.

\section{ABSTRACT}

In the Brazilian electroportable market, it can be seen that few brands have their corporate culture focused on innovation. The aim is to investigate the process of innovation within an ident of household appliances. The alignment of design trends with consumer behavior brings inspiration to differentiate itself from the products offered by the competition. Cadence, a Brazilian brand that began its journey importing small appliances from China, felt the need to innovate and incorporate design into its DNA. Through a case study and an on-site research process, it was possible to identify the innovation and design thinking of the Colors line launched by the company in 2013 , in this way it was identified that the innovation process was based on the experience of use for The design of the shapes and color trends for the segment, this way the product came to integrate to its environment of use as a decorative item.

\section{INTRODUÇÃO}

Observando o mercado de eletroportáteis, percebe-se uma grande oportunidade de trazer novidades para os consumidores. É um mercado muito competitivo, onde as empresas limitam-se a oferecer apenas o que já é oferecido pelos concorrentes e entram na guerra de preços, muitas vezes descartando a 
importância da qualidade e do design.

Com a massificação de produtos vindos da China, não é difícil encontrar produtos iguais nas prateleiras. Em busca dessa diferenciação, a marca Cadence vem estruturando sua equipe interna com um núcleo de design, que acompanha o desenvolvimento dos produtos desde a sua concepção até o lançamento, preocupando-se com cores, design e qualidade. A partir de uma pesquisa exploratória e de observação, será possivel demonstrar as inovações da empresa e com o uso de entrevistas entender como a equipe de design iniciou o processo de concepção dos produtos.

Esse artigo objetiva estimular a cultura de inovação nas empresas, onde o design precisa estar atrelado aos valores das companhias. Em um estudo de caso e através de visitas e entrevistas com o Team Design/Marketing, foram investigados conceitos de design e inovação e como eles atingem e influenciam o comportamento do consumidor no mercado de eletroportáteis, que atualmente sofre grande interferência das tendências internacionais. Como exemplo à inovação, é citado o case da linha Colors da Cadence, que foi um dos marcos de inovação da marca até o momento.

\section{DESIGN E INOVAÇÃO}

É através do design que um produto se torna muito mais atrativo e competitivo no mercado, seja pela sua beleza, função ou pela experiência que causa. "A empresa que almeja crescimento deve tornar-se brilhante em usar o design para proporcionar uma experiência fabulosa para o consumidor" (BRUNNER; EMERY, 2010, p. 18).

O atual cenário, das indústrias de eletrodomésticos, demonstra que as empresas passaram a perceber a necessidade de voltar sua cultura de inovação para o design, contribuindo com seus processos desde a fase de investigação. O processo de design envolve muito mais do que o briefing e a geração de alternativas. Para o sucesso efetivo do projeto, ele precisa ser planejado do início ao fim, onde criatividade, estratégia e inovação devem ser alinhadas e trabalhadas em conjunto. Nesse contexto, o designer passa a ser figura principal do elenco. Deixa de ser apenas um criativo e expert de softwares para tomar conta também dos processos estratégicos nas empresas, participando de todas as etapas do desenvolvimento de produtos, e não somente a fase de criação.

A inovação bem-sucedida requer o aperfeiçoamento de produtos e de processos organizacionais. $\mathrm{O}$ design cria valor em ambas as áreas. Além disso, a inovação é um processo coletivo e interativo que está próximo da 
realidade do processo de design, uma vez que combina fatores internos e externos. $O$ design é valorizado tanto pela qualidade superior do produto quanto pelo processo superior de DNP. (Mozota, 2011, p. 146)

A constante evolução do mercado, os avanços tecnológicos e o ciclo de vida cada vez mais curto dos produtos traz instabilidade ao setor, o que colabora com a forte demanda por inovação.

A inovação parte de uma necessidade dos clientes e termina com a realização dessa necessidade e avaliação da satisfação do usuário, ou seja, ela inicia e termina no mercado.

De acordo com Day (2001, p.29), "as empresas orientadas para o mercado não estão preocupadas apenas em perceber as necessidades dos clientes, mas também em prever os movimentos das rivais no mercado". É preciso conhecer e estar atento a tudo o que acontece com os concorrentes para ser competitivo em meio a tanta inovação.

Segundo Keller e Kotler (2012), a inovação precisa ser contínua em tempos de economia em rápida mutação. As empresas com alto potencial inovador identificam rapidamente novas oportunidades de mercado, criam uma atitude positiva em relação ao risco, transformando a inovação em algo rotineiro, permitindo que os funcionários experimentem e até falhem. Um exemplo é o case do Post-it da marca $3 \mathrm{M}$, produto que teve sua origem no erro, que foi a criação de um adesivo que colava, mas soltava facilmente. Inicialmente a ideia foi descartada, e mais de 10 anos depois foi utilizada na função de adesivo em blocos de notas, uma das maiores inovações da empresa.

Quando se fala em inovação, é preciso considerar os riscos, onde muitas vezes é necessário apostar alto para se destacar com competitividade no mercado. “Em design, risco não é um palavrão. Você precisa se arriscar para chegar a algum lugar" (BRUNNER; EMERY, 2010, p. 179).

Lançar produtos rapidamente e com frequência é uma forte característica das empresas orientadas para o mercado e com foco em inovação através do design. Elas acreditam que o produto não precisa estar perfeito para entrar no mercado, mas pode ir melhorando de acordo com o feedback dos clientes. A Apple foca no design como experiência, pois o ipod tornou-se não só um objeto de desejo, mas um ícone em experimentação contínua, já que foi sendo aperfeiçoado de acordo com as necessidades dos consumidores.

Um bom produto não é suficiente para o sucesso da inovação: estudos anteriores enfatizam a importância da gestão no desempenho da inovação. Nesse processo, o design cria valor porque participa da melhoria da 
qualidade do processo de DNP, da definição da estratégia de produto e da qualidade das equipes de novos produtos. (MOZOTA, 2011, p. 145)

Segundo (Baxter, 2011), uma estratégia bem definida é o elo entre a criatividade e a inovação. Desta forma o planejamento estratégico é baseado nesse posicionamento e pode ser classificado como: ofensivo, defensivo, tradicional ou dependente.

As empresas que querem manter a liderança no mercado e investem muito em pesquisa e desenvolvimento, tem seu planejamento estratégico posicionado de forma ofensiva; enquanto as empresas que seguem as líderes adotam o defensivo, que apresenta baixo risco. $\mathrm{O}$ tradicional é utilizado por empresas em mercados estáveis, que não tem demanda por mudança; e o dependente é adotado pelas empresas que não tem autonomia para lançar seus próprios produtos.

Na teoria de Drucker (1986, p. 301), existe uma estratégia chamada "imitação criativa", que se assemelha com a estratégia defensiva citada anteriormente. $\mathrm{O}$ autor defende que apesar de ser uma contradição de termos, é possível ser criativo através de uma imitação, pois o imitador criativo não cria um novo produto ou serviço, mas os melhora e posiciona o produto no mercado, pois consegue observá-los sob o ponto de vista do cliente.

Um bom resultado dado pelo design necessita planejamento, gerenciamento, criatividade e tecnologia, assim gerando inovação, agregando valor aos produtos e trazendo diferenciais competitivos. Ou seja, uma ideia inicial passa por várias etapas para se tornar viável, onde não basta ser criativo, é preciso elaborar uma estratégia que faça com que a inovação seja eficaz.

\section{COMPORTAMENTO DO CONSUMIDOR CONTEMPORÂNEO}

As casas, famílias, alimentos e hábitos das pessoas vêm mudando com o passar dos anos. A vida é muito corrida e as horas parecem passar mais rápido que antigamente, falta tempo para vivenciar momentos com a família, praticar atividades de lazer, entre outros. Em um mercado extremamente competitivo, é essencial saber como se comporta o público alvo que se quer atingir.

De acordo com Solomon (2011, p. 33), o comportamento do consumidor "é o estudo dos processos envolvidos quando indivíduos ou grupos selecionam, compram, usam ou descartam produtos, serviços, ideias ou experiências para satisfazer necessidades e desejos". Para o autor, a necessidade surge primeiro, como uma motivação básica. Quando ela é percebida, surge o desejo, que é o modo de satisfazer essa necessidade. Ao identificar o que o cliente quer, fica 
mais fácil direcionar produtos e campanhas que influenciem as compras. Corroborando Keller e Kotler (2006, p. 55), "já não basta simplesmente satisfazer clientes. É preciso encantá-los". Estudando o comportamento dos clientes, é possível conhecer os desejos de consumo e entender o processo de tomada de decisões, saber como os consumidores optam por determinado produto ou serviço e como o utilizam. Drucker (1986, p. 266) defende essa ideia, mencionando que "a nova empresa precisa introduzir práticas sistemáticas para lembrar-se de que um produto ou serviço é definido pelo cliente e não pelo produtor".

Sendo assim, é preciso conhecer a fundo o público alvo, percebendo suas reais necessidades e o valor que os produtos proporcionam a ele. $O$ que os consumidores mais buscam nas prateleiras, são produtos que eles possam se identificar, que se pareçam com eles, ou com o que eles gostariam de ser. De acordo com Keller e Kotler (2012), a escolha por um determinado produto ou serviço pode ser motivada por diversos fatores, que podem ser culturais, sociais e pessoais; como algo que foi vivido na infância, uma tradição da família ou do grupo social que a pessoa está inserida, da idade e período da vida que está passando, ou do contexto político e econômico da época.

Os periodos de economia variam monetariamente de acordo com a proposições políticas adotadas pelos governos mundiais. Implica diretamente no poder de compra da população. Em períodos de crise, o consumidor tenta gastar apenas o estritamente necessário. Acompanhando as notícias é possível perceber a dificuldade que está sendo para vários segmentos se manterem no mercado. Conforme noticia publicada em O Negócio do Varejo (2015):

O preço é decisivo quando a crise aperta, mas não é o único fator considerado pelo brasileiro na hora da compra. Menos impulsivo, o consumidor quer manter as marcas habituais e, para isso, está disposto a pesquisar mais, ir a redes mais distantes e substituir as idas semanais ao supermercado por visitas mensais.

A busca por marcas conhecidas e tradicionais traz mais segurança ao consumidor, fato que não acontece na busca por preço, onde ele se sujeita a testar uma marca desconhecida, correndo um risco que não está disposto a passar em um momento de instabilidade econômica. Essa instabilidade faz com que muitos consumidores deixem de gastar com o que não é essencial.

No entanto, há um certo espanto (de maneira positiva) ao ver a pesquisa do IBGE (2016) relatando que no mês de março de 2015 os eletroportáteis não tiveram queda na fabricação, e sim, aumentaram em 13,9\%. Um aumento bem expressivo em relação a queda de $-4,8 \%$ nos automóveis, de $-2,1 \%$ dos eletro- 
domésticos da linha branca e os -35\% dos eletrodomésticos da linha marrom. Os eletroportáteis têm uma maior resistência nos períodos de economia mais difícil, porque eles têm um valor menor em relação aos eletrodomésticos e mais canais de distribuição. $O$ estudo do comportamento do consumidor está inteiramente ligado à definição de tendências, onde é necessário conhecer muito o mercado e estar bem informado acerca do que está acontecendo no mundo. Saber como o cliente pensa, no que acredita, o que sonha, onde vai, quais seus medos e desejos, ajuda a entender como ele toma decisões de compra e que produtos vão realmente trazer valor para o grupo consumidor selecionado.

\section{TENDÊNCIA EM ELETRODOMÉSTICOS}

Para todas as ações que são feitas no cotidiano, existem pequenos objetos que fazem toda a diferença na rotina das pessoas: os eletrodomésticos.

Eles surgiram no início do século XX com o objetivo de facilitar as tarefas domésticas e hoje em dia são essenciais dentro de casa. Inicialmente os eletrodométicos tinham um uso mais industrial, muitos eram aparelhos mecânicos que transformaram-se em aparelhos elétricos.

Segundo Martins (2013), a primeira empresa que inovou em trazer design para esses produtos, foi a alemã AEG, que em 1907 contratou o arquiteto Peter Behrens para trabalhar no projeto da fábrica, logotipia e o redesign de produtos como o ventilador e a chaleira elétrica.

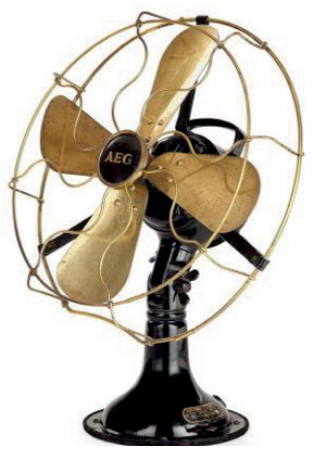

Figura 1 - Ventilador assinado por Peter Behrens. Fonte: Imagem de arquivos dos autores (2015)

De acordo com Martins (2013), nos anos 60 os eletrodométicos passaram a ter linhas mais retas e nos anos 70 foram introduzidas as cores. Na década de 90 , a cor predominante era a branca, e logo depois surgiram produtos na cor preta e com acabamentos em inox. Esses padrões seguiram dominando o mercado até os dias de hoje, eletrodomésticos como geladeira, fogão ou máquina de 
lavar, quanto eletroportáteis como cafeteira, liquidificador ou sanduicheira, todos facilitam as tarefas diárias, de acordo com suas funcionalidades originais. $\mathrm{O}$ que mudou de uns tempos para cá, é que hoje, além de funcionais, os eletrodomésticos seguem tendências e ditam estilo, adequando-se às cozinhas e à personalidade das pessoas.

No contexto da moda em geral, as tendências ajudam a guiar e definir novas coleções. Elas são ditadas por grandes nomes e geralmente seus conceitos são apresentados em desfiles e feiras de lançamentos, no setor dos eletrodomésticos, a escolha dos produtos que vão entrar no portfólio têm forte inspiração comercial, ou seja, no que estão vendendo. É um mercado que é, ao mesmo tempo, conservador e inovador pelo fato de ser muito competitivo, e precisa ter constantes novidades em produtos, tecnologia, funções e opções de preço. A maior parte das marcas de eletrodomésticos do Brasil costumam adotar um posicionamento defensivo, enquanto que as pioneiras, como a Arno e a Philips Walita, são as marcas que adotam uma postura ofensiva e trazem a inovação para o mercado. As tendências são ditadas pelas marcas líderes e, após o seu lançamento, produtos semelhantes ou até melhorados aparecem nas prateleiras, seguindo o conceito de imitação criativa já explorado anteriormente.

"O imitador criativo não inventa um produto ou serviço; ele o aperfeiçoa e o posiciona", define Drucker (1986, p. 306). Segundo ele, a imitação criativa não se alimenta das fraquezas dos pioneiros, ela precisa do sucesso para ser bem aplicada em novos produtos.

As tendências estão fortemente ligadas ao comportamento dos consumidores, então elas mudam o tempo todo. O um exemplo é a fritadeira sem óleo. Os consumidores querem levar uma vida mais saudável, e esse comportamento gerou a necessidade de um novo produto. A primeira fritadeira sem óleo foi lançada pela Philips Walita.

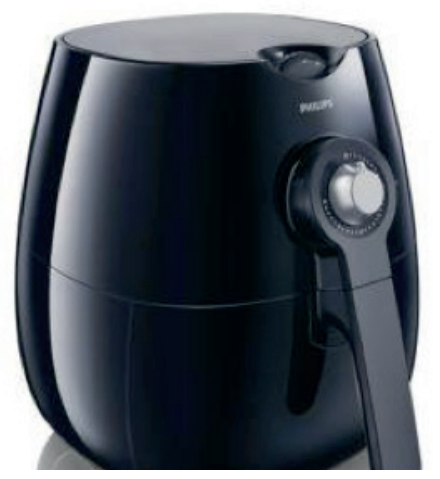

Figura 2 - Fritadeira sem óleo da Phillips Walita. Fonte: Imagem de arquivos dos autores (2015) 
O sucesso desse produto abriu mercado para tantas outras marcas que passaram a oferecê-la em seu portfólio e fechou o mercado para as antigas fritadeiras que estão obsoletas porque não evoluíram em termos de tecnologia e design. Ou seja, o consumidor mudou o seu hábito ao conhecer um novo produto e acreditar nas suas vantagens.

Um produto que há 5 anos atrás não existia, hoje é um sucesso comercial e se consolidou no mercado. Seguir uma tendência não é a certeza de que o produto vai dar certo, mas o estudo em cima disso evidencia o que é mais importante para que se possa fazer uma aposta mais assertiva.

No âmbito da moda as previsões também precisam ser bem antecipadas seguindo o mesmo princípio para lançar eletroportáteis, pois o tempo total de desenvolvimento, desde a ideia inicial até o lançamento é de 9 a 12 meses. A exemplo disso, em 2013 a Arno lançou juntamente com a Rochedo uma linha de eletroportáteis e panelas com ilustrações da estilista Adriana Barra' .

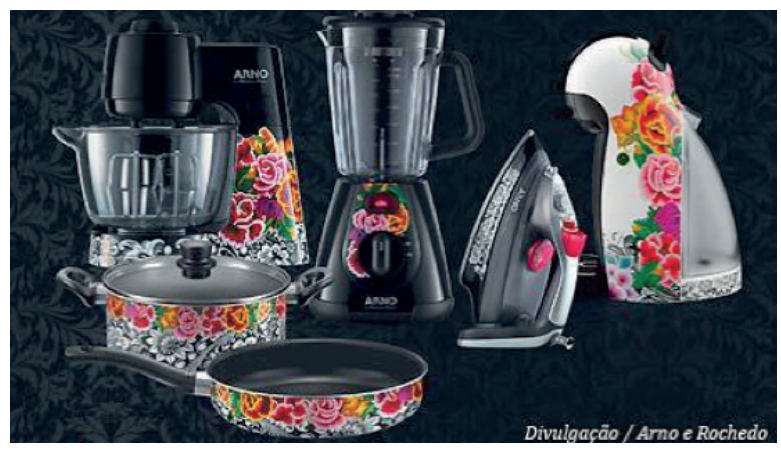

Figura 3 - Produtos Arno \& Rochedo.

Fonte: Imagem de arquivos dos autores (2015)

Embora com muito conteúdo para ser estudado, o setor de eletrodomésticos tem pouca abordagem no cenário do design. Sobre tendências, comenta-se muito sobre a necessidade que as pessoas tem de estarem conectadas, gerando assim uma invasão da internet em todos os setores. E os produtos domésticos estão aderindo cada vez mais a essa tecnologia.

Esse fenômeno deu origem ao termo Internet das coisas (ou loT = Internet of Things), que indica um futuro que já está acontecendo em vários eletrodomésticos, como é o caso do modelo de refrigerador da Electrolux, ele ajuda a

$1 \quad$ Adriana Barra nasceu em Londrina em 1974. É formada em Moda, Fotografia e estudou Design de Interiores e artes em Florença, na Itália. A designer é especialista em estamparia, e seu trabalho pode ser reconhecido através das cores fortes, muitos detalhes e pelos florais. Seus trabalhos são divertidos e marcantes. 
melhorar o contato com os consumidores através do envio de receitas, serviços de manutenção preventiva e outras funções por meio da conexão streaming.

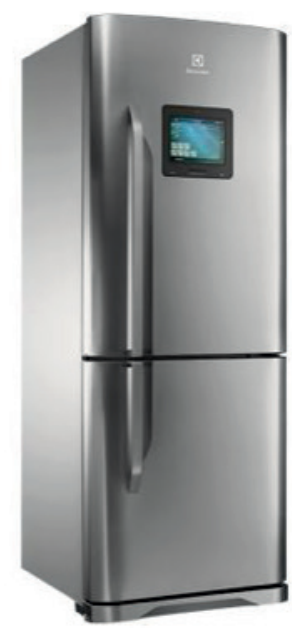

Figura 4 - Refrigerador da Electrolux.

Fonte: Imagem de arquivos dos autores (2015)

Segundo Zambarda (2014), já temos muitos objetos conectados nos dias de hoje, como geladeiras, carros, óculos e elevadores. A internet das coisas vem crescendo com o apoio de grandes empresas, e pode intervir em pequenos objetos ou até em complexas infraestruturas.

No contexto dos eletrodomésticos, eles passam a fazer mais do que suas funções básicas. Ligados a uma conexão com a internet, eles podem funcionar como robôs, indicando receitas, quando um componente deve ser trocado, os prazos de validade dos alimentos que contém, dentre tantas outras funções.

Um setor importante no cenário da loT é a Casa Inteligente (ou Smart Home). A loT trará grandes contribuições para a Casa Inteligente tais como segurança \& alarme, controle da iluminação, gerenciamento de energia elétrica, eletrodomésticos conectados, entre outros serviços/comodidades. Nesta Casa os eletrodomésticos serão - com certeza - "coisas" a serem conectadas na Internet". Esse conceito também foi bastante explorado na maior feira de tecnologia que acontece todo ano em Las Vegas, a CES (Consumer Electronics Show). São eventos como esse que ditam tendências e mostram o caminho para as empresas, já que não existe muito material de design focado em eletrodomésticos. (Prado 2015, p.1)

Frequentar eventos para ver as novidades do mercado mundial é essencial para as empresas de eletrodomésticos não ficarem alienadas e resignadas apenas 
aos passos a concorrência. É uma experiência muito válida no campo das tendências, pois é uma excelente fonte de inspiração para os designers, que pode possibilitar o surgimento de grandes inovações.

\section{CASO CADENCE COLORS}

A Cadence é uma marca de eletrodomésticos e eletroportáteis que iniciou sua trajetória na cidade de Caxias do Sul/RS em 1999, quando o empresário Sr. Nelson Lisot trouxe um produto inovador para o mercado brasileiro da época: a panificadora doméstica. A empresa cresceu importando produtos da China, e foi aumentando o portfólio rapidamente. Em 2010, a sede mudou-se para Navegantes/SC e hoje em dia conta com mais de 200 produtos em linha e cerca de 300 funcionários, além de ter fabricação nacional e design exclusivo.

Em maio de 2014, a Cadence passa a integrar o grupo Jarden Consumer Solutions (JCS), que tem sede na Flórida e emprega mais de 4.000 pessoas em 16 países. JCS é parte da Jarden Corporation, líder global de produtos de consumo com mais de 120 marcas vendidas em mais de 100 países ao redor do mundo.

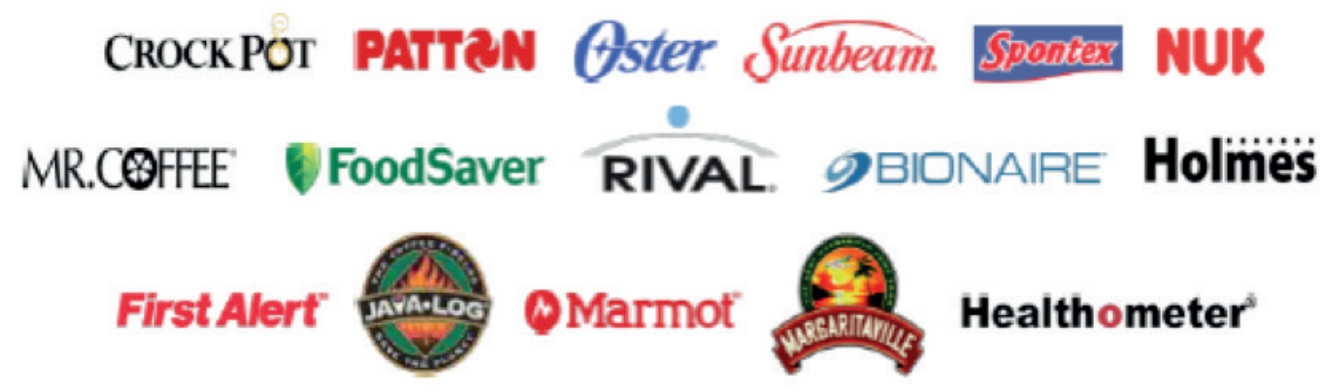

Figura 5 - Algumas marcas do grupo Jarden.

Fonte: Arquivos Cadence (2014)

EM 2015, as marcas Oster, Cadence e First Alert fazem parte da JCS Brasil; que terá suas futuras instalações sendo construídas em Piçarras - SC, em um novo centro de distribuição com uma área inicial de $30 \mathrm{mil} \mathrm{m}^{2}$ para atender a todas as marcas. A Cadence tem um mix de mais de 200 produtos, com modelos, cores e diferentes tecnologias. Atualmente está entre as líderes do mercado de eletroportáteis e tem 5 principais departamentos: cozinha, conforto térmico, beleza e saúde, lar e eletrodomésticos. Sua maior participação é dentro da divisão de cozinha, que compreende batedeiras, cafeteiras, fritadeiras, liquidificadores, panelas de arroz, sanduicheiras e panificadoras - produtos que representam $40 \%$ de seus negócios. 
Na sequência, estão os itens de conforto térmico (aquecedores, climatizadores, umidificadores e ventiladores), com 25\%; a linha de beleza e saúde (pranchas, escovas e secadores de cabelo), ocupando $20 \%$ e os produtos para o lar (aspiradores e ferros de passar), com 15\%. Também trabalha com linhas especiais, como a Gourmet (itens como frigobar, adegas, cooktops e coifas), Chiaro, Kobalt e Cobreo (linhas profissionais com pranchas, secadores, depiladores, cortadores de cabelo e escovas rotativas), Colors (mix de 8 produtos de cozinha em 4 opções de cores) e Cozinha Criativa (produtos diferenciados como máquina de cupcake, donuts, waffle, panquequeira, sorveteria, crepeira, pipoqueira, e outros).

$O$ desempenho dos produtos, da linha cozinha tem atingido um execelente nível, apresentando combinação da preocupação com funcionalidade, praticidade e simplicidade para seus usuários, condizendo para um crescimento sustentável e incorporando uma política de inovação na concepção de novos produtos. Esta relação com os usuários da marca Cadence, tem o objetivo de transformar a experiência de uso em um momento único na utilização dos produtos.

Deste modo apostou-se no design como diferencial competitivo em seus produtos e materiais gráficos, incorporando um processo de inovação desde a concepção dos produtos até a embalagem que vai comunicar no ponto de venda com o consumidor. No Núcleo de Design Cadence é onde as necessidades dos consumidores ganham forma e cores através de 15 profissionais, entre designers gráficos, de produto e profissionais de marketing, que trabalham para transformar simples produtos em objetos de desejo. A empresa busca através de seu processo as melhores soluções com produtos inovadores que vão ao encontro das exigências do consumidor.

Para adotar o design como fator competitivo e de inovação em seus produtos a marca Cadence, incorporou o processo de design baseado na Metáfora “Duplo Diamante", definida pelo Design Council, na Inglaterra (Design Council, 2011), que propõ-se a ser dividido em quatro fases:

- Descobrir: Descobrir: marca o início do projeto, por uma idéia ou inspiração, muitas vezes resultante de uma etapa de descoberta na qual as necessidades dos futuros usuários são identificadas. Essa fase inclui atividades como: pesquisa de mercado, pesquisa sobre o usuário, gestão da informação e grupos de pesquisa-design.

- Definir: Fase em que a interpretação das necessidades do projeto e do usuário são alinhadas com os objetivos do negócio: As principais atividades dessa eta- 
pa são: desenvolvimento do projeto, gestão do projeto e aprovação.

- Desenvolver: Início da execução do que foi projetado, onde as soluções são desenvolvidas e testadas iterativamente. Constam atividades como: trabalho multidisciplinar, gestão visual, métodos de desenvolvimento e testes.

- Entregar: Fase em que o projeto é finalizado e lançado no mercado definido. Asatividades dessas etapas são: teste final, aprovação e lançamento, assim como, avaliação por metas e ciclos de feedback.

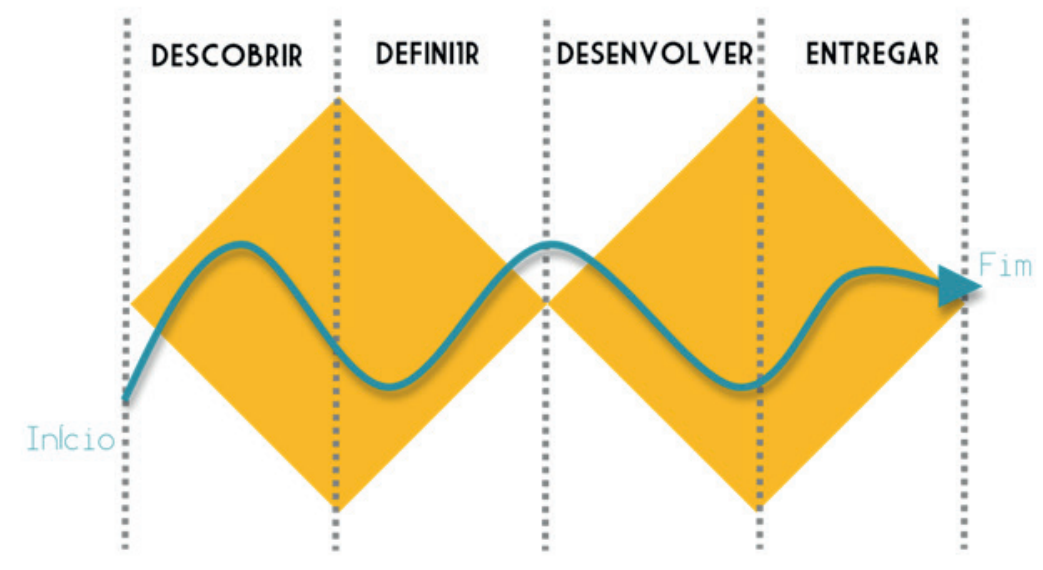

Figura 6 - Modelo de Processo de Design Duplo Diamante Fonte: Adapatado de Design Council (2011)

A implementação de um processo de design pela Cadence deu-se a preocupação com a configuração dos produtos, as cores e acabamentos sempre foram cuidadosamente selecionados. Na hora de estudar o layout para um determinado produto, sempre havia alguma restrição, com o "medo" de que os clientes (donos de grandes lojas varejistas) pudessem deixar de comprar por ser um mercado muito conservador.

De acordo com Brown (2010), uma organização que consegue entender melhor seus clientes, atenderá melhor às necessidades deles, para o autor essa é a fonte mais segura de lucratividade em longo prazo e crescimento sustentável. Por outro lado, os clientes querem ser entendidos, estão mais exigentes, com diferentes tipos de demanda, se relacionando de formas diferentes com as marcas, 
deixaram de ser consumidores passivos para participarem do desenvolvimento do produto que lhes será oferecido e esperam um relacionamento além do ponto de venda.

A prática do processo de design na concepção do produto assegura o sucesso da empresa, a dinâmica de inovação criada se assemelha muito a um processo industrial e complementa-se também a técnicas oriundas do Design Thinking, como o mapeamento e reuniões transdisciplinares onde as ideias entram como matéria prima (como um porduto industrial) passando por fases até chegarem a etapa de materialização e tornarem-se produtos tangíveis.

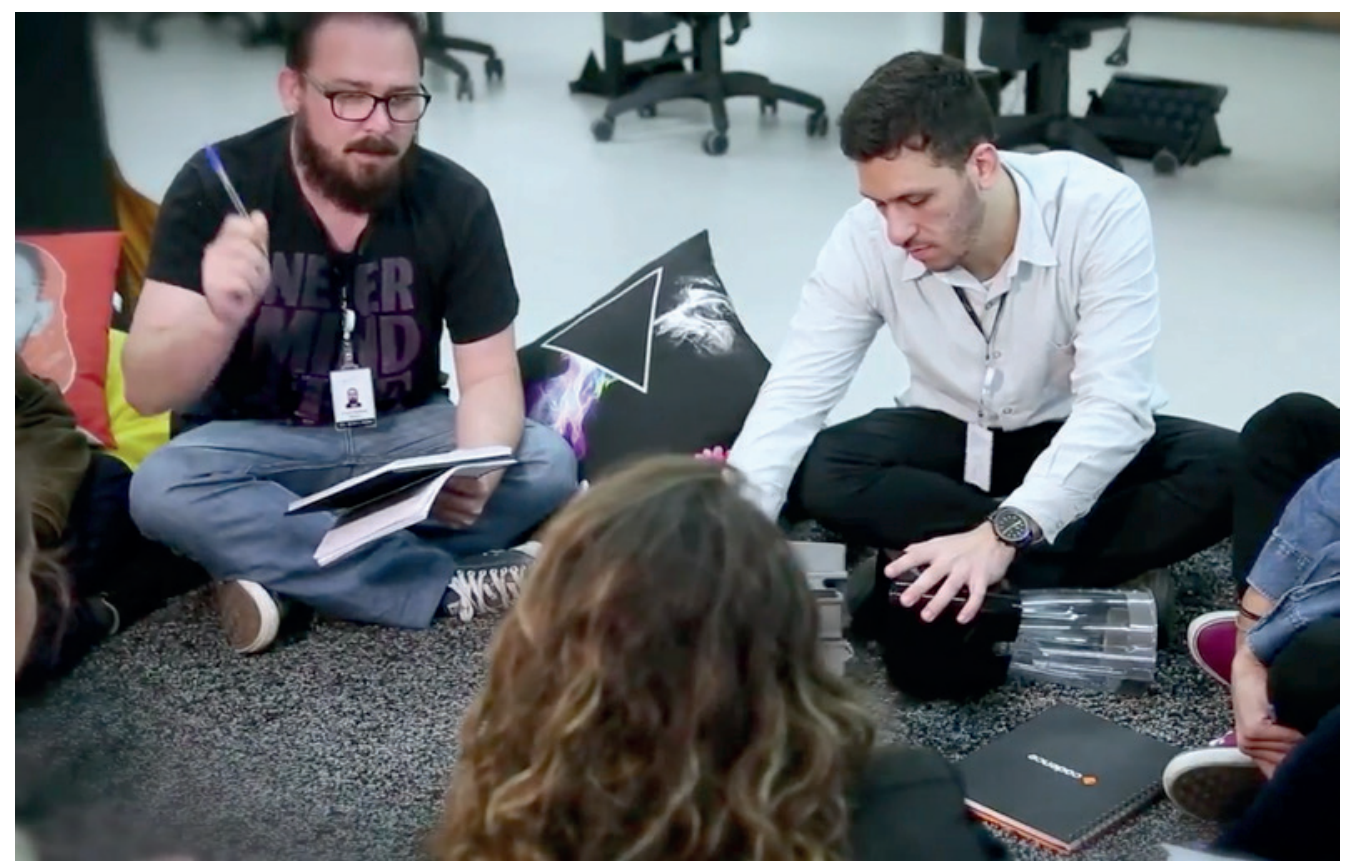

Figura 7 - Reunião inicial com os Atores do Projeto - Fase Descobrir

Fonte: Arquivos Cadence (2014)

A primeira etapa desse processo é a reunião onde um grupo se reúne periodicamente para avaliar as sugestões mais promissoras que oriumdam-se de diferentes fontes como: workshops, palestras, intranet, ou até mesmo das parcerias internas. Para o desenvolvimento da nova linha de produtos observou-se um potencial mercado onde a têndência baseava-se em eletroportáteis que se incorporavam os ambientes e eram expostos como objetos de decoração. Desta forma observou-se que até então as cores predominantes nos eletroportáteis eram o branco, preto com detalhes em inox. A única cor que aparecia em alguns produtos era o vermelho, que aos poucos era introduzido em produtos da marca Arno. Através de pesquisas de mercado e viagens para feiras internacionais, 
percebeu-se a forte tendência do colorido vinha ganhando força em eletrodomésticos e eletroportáteis. As cores já eram bastante exploradas em produtos como a tradicional batedeira da KitchenAid e Kenwood

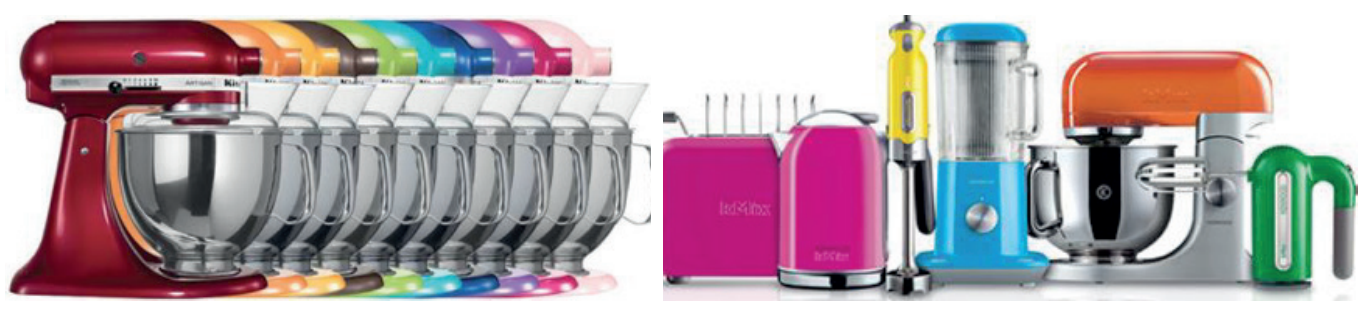

Figura 8 - Produtos da KitchenAid e Kenwood Fonte: Imagem de arquivos dos autores (2015)

Ambas as marcas têm produtos de alto valor agregado, que são vendidos no Brasil através de lojas do ramo a um valor compatível com a classe A. No cenário brasileiro, a Arno já tinha alguns eletroportáteis na cor vermelha e a Brastemp tinha frigobares com estilo retrô nas cores vermelho, amarelo claro e azul claro.
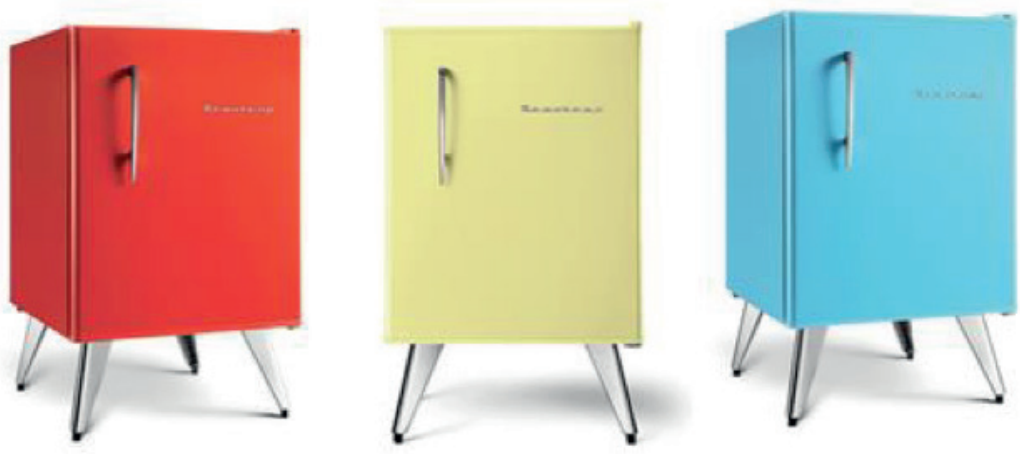

Figura 9 - Frigobares da Brastemp.

Fonte: Imagem de arquivos dos autores (2015)

Desta forma, o cenário brasileiro estava propício a aceitar a tendência nesse momento. Por mais conservador que fosse o mercado, havia uma tendência com grandes chances de estourar. Drucker (1986) diz que as estruturas das indústrias parecem ser muito estáveis, mas que uma mudança na estrutura do mercado ou da indústria constitui também uma importante oportunidade para inovação. A oportunidade de trazer eletroportáteis coloridos para um universo em preto e branco, aliados a um preço competitivo e ao timing certo demonstrado nas pesquisas, resultou na penetração da marca neste nicho de mercado que aliado as tendências da época aumentou seu mix de produtos. Em outubro de 2012, 
a tendência estava confirmada e iniciaram-se os estudos da linha que teria seu lançamento na maior feira do segmento, a Eletrolar, em julho de 2013.

"E, no entanto, o momento oportuno é essencial. Quando se explora mudanças na percepção, a'imitação criativa' não funciona. Tem-se que ser o primeiro. Mas, precisamente por haver tanta incerteza em saber se a mudança na percepção é uma novidade passageira ou algo permanente, e quais são realmente as consequências, a inovação baseada na percepção deve começar pequena e ser bem específica" (DRUCKER, 1986, p. 147).

Nesta etapa da definição buscou-se qualificar os dados obtidos na coleta de informações e qualificá-los em soluções que originam ideias e insights levando em conta a análise de tendências e a mudança de comportamento dos consumidores. Desta forma a orientação do desenvolvimento do produto deve ser orientada de acordo com as atitudes do usuário (consumidor), independente neste momento de sua faixa de renda. O portifólio de produto deve ser segmentado em consonância com as atitudes e comportamentos do consumidor e os contextos de onde este produto está inserido a exemplo do ambiente cozinha, onde a busca pela satisfação de cozinhar e gourmetização da comida pode ser um atributo para ampliar mais benefícios do produto. Esta questão definiu critério de seleção do portfólio inicial de produtos além da capacidade produtiva dos fornecedores. Para lançar os produtos inicialmente foram escolhidas algumas cores para as primeiras amostras, que foram submetidas a avaliação, selecionadas foram batizadas com os nomes: vermelho cereja, amarelo canário, azul pistache e roxo berinjela. A linha de eletroportáteis delimitou-se a 4 primeiros produtos: cafeteira, sanduicheira, chaleira elétrica e batedeira.

Para o desenvolvimento, nesse sentido, inicia-se a etapa de ideação, que consiste no processo de gerar, desenvolver e testar ideias. Quando os conceitos começam a tomar forma, pormeio da realização de protótipos representativos das ideias.

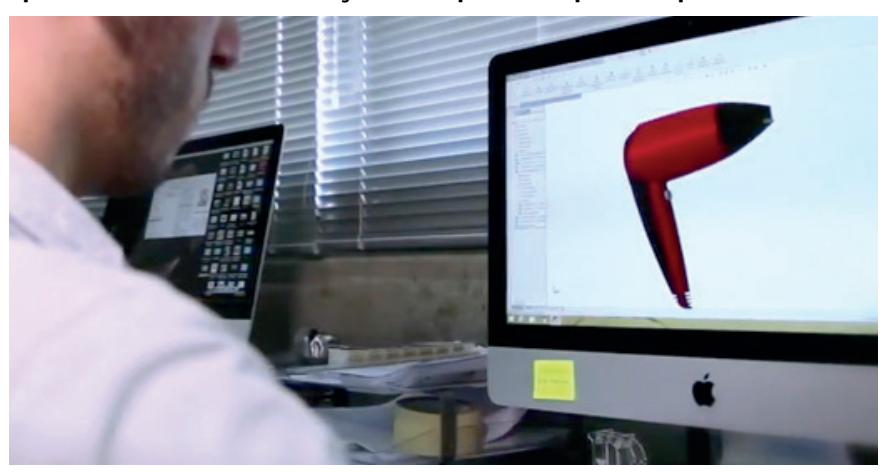

Figura 10 - Modelamento 3D das ideias após rought. Fonte: Imagem de arquivos dos autores (2015) 
Para a equipe de design da Cadence independentemente da fase utilizam-se protótipos ao longo de todo o processo ocorrendo em paralelo com a idéia, dessa forma pelos protótipos é que se verifica se e a idéia é relevante ou não para os consumidores. Os protótipos ainda podem ser conceituais de imagens, formas e funcionalidade, dependendo da finalidade e objetivos do projeto, assim como suposições a serem validadas.

Umas das formas mais atuais de se fazer isso e enteder se a concepção da forma do produto está de acordo com a a premissas do projeto é a tecnologia de impressão 3D, que possibilita de forma rápida construir um modelo físico do produto que está em desenvolvimento para avaliação, podendo surgir novos insights através de testes realizados no modelo ou protótipo. Quanto mais cedo, validam-se as ideias, fica mais fácil de identificar a melhor solução, e ainda mais próximo da realidade destaca a Equipe de Design.

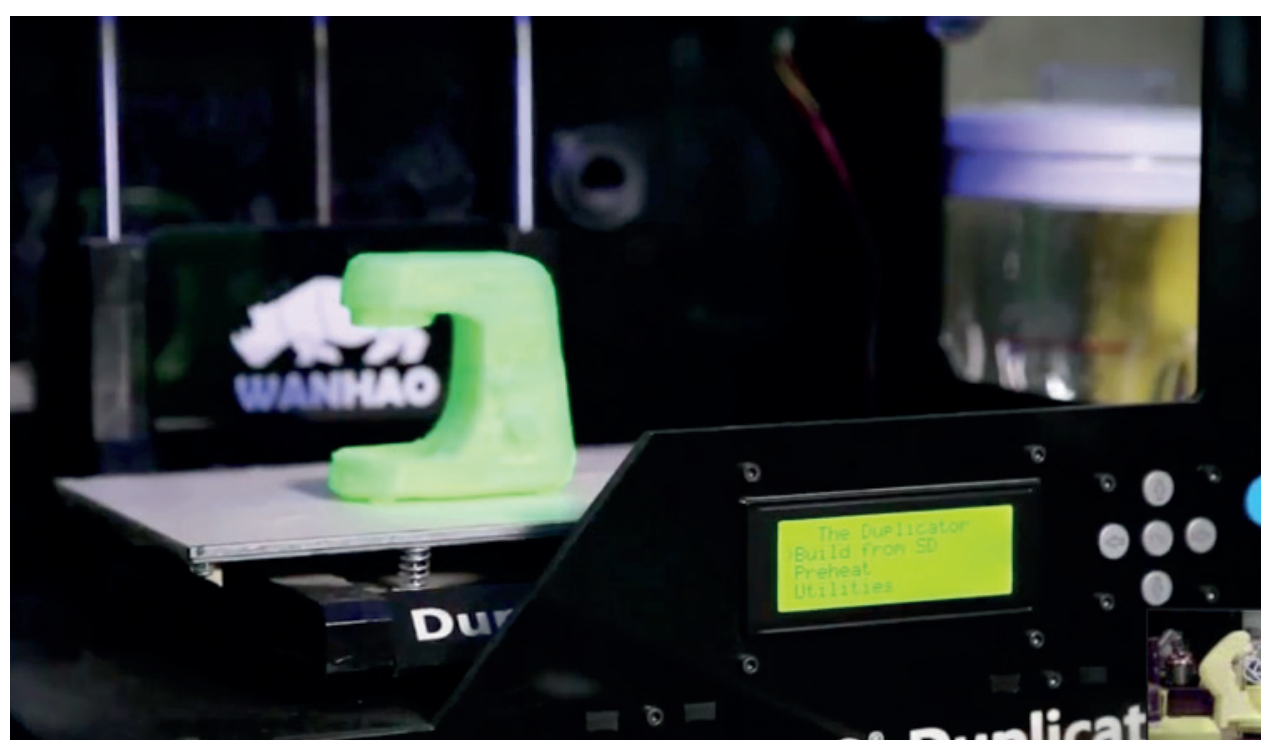

Figura 11 - Impressão 3D do Eletroportátil

Fonte: Imagem de arquivos dos autores (2015)

A confecção dos protótipos em fábricas da china criou uma preocupação com os diferentes tons de cores sendo produzidos em diferentes fornecedores, deste modo a experimentação dos protótipos fez com que os concepts dos produtos fossem injetados várias vezes, o que demandou um bom tempo até chegar no padrão exato escolhido para haver uma boa consistência de cor em todas as peças, pois uma diferença de tonalidade na linha poderia desvalorizá-la. 


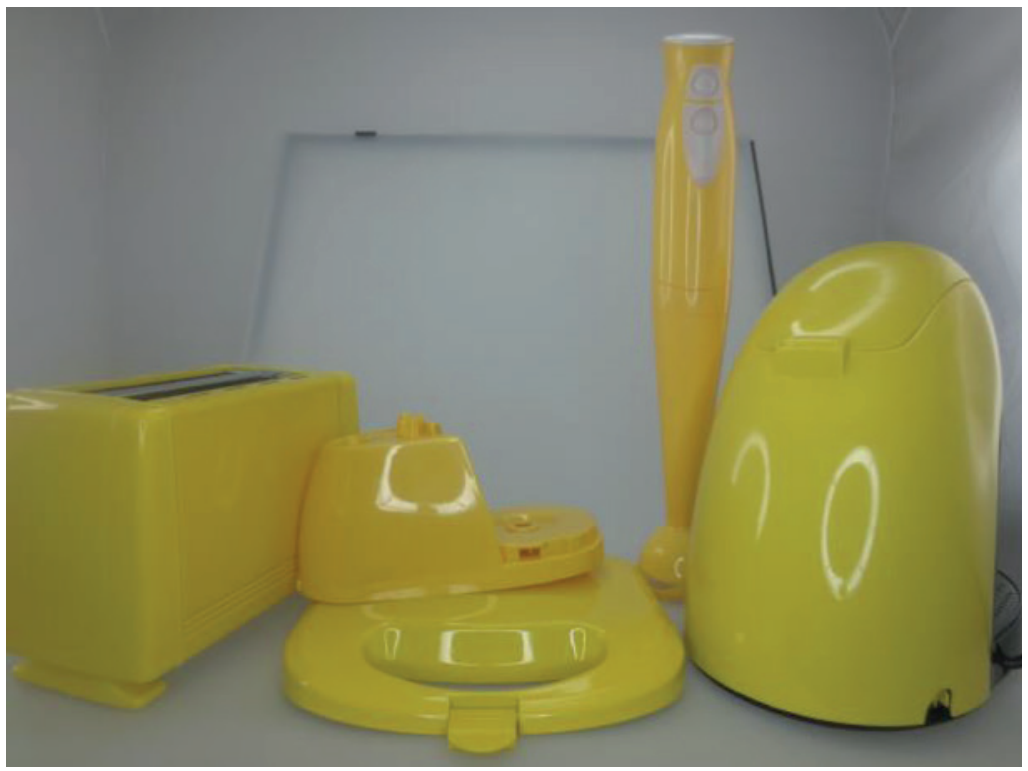

Figura 12: Amostras de cores

Fonte: Arquivos Cadence (2014)

A dificuldades de validar as cores mesmo utilizando um padrão internacional Pantone, sempre havia alguma amostra que destoava do padrão tonal cromático estabelecido como demonstrado na Figura 12. Isso exigiu uma grande sintonia entre o núcleo de design e o escritório na China. Quando se chega a melhor solução possível, e aprovada dentro dos critérios e restrições, a próxima etapa refere-se ao Desenvolvimento e Entrega, à Implementação, é o percurso que vais do design até o mercado. Refere-se à produção e comunicação do produto.

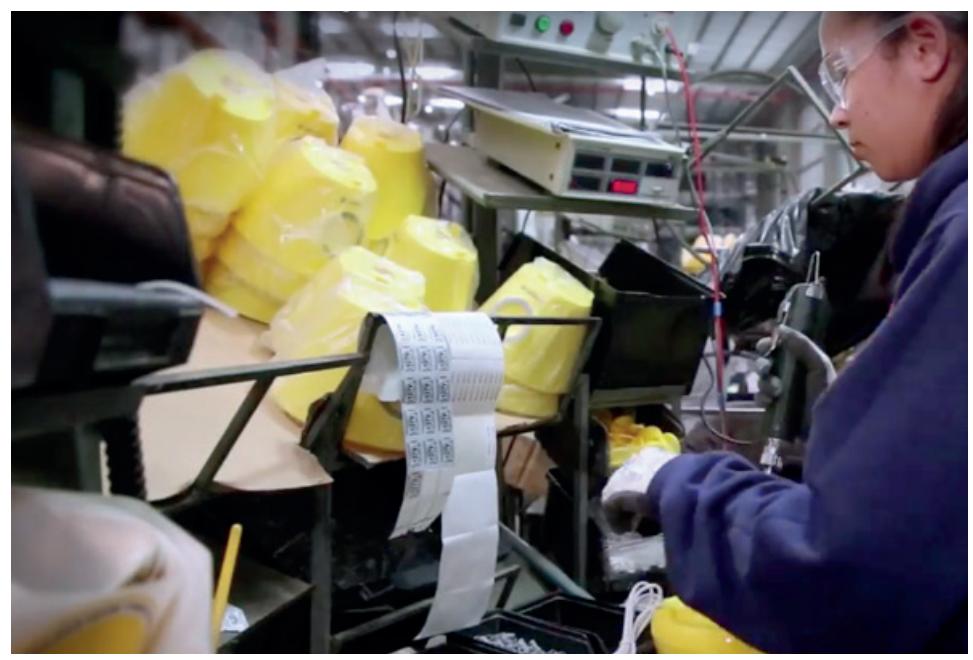

Figura 13: Processo Produtivo

Fonte: Imagem de arquivos dos autores (2015) 
A comunicação de maneira clara deve fazer com que todos os envolvidos no projeto e os que vão ser atendidos por ele entendam a mensagem que se quer passar. Na Cadence a equipe de Marketing que trabalha integrada com a de Design, solicita-se que o profissional responsável pelo desenvolvimento das estratégias acompanhe o processo de desenvolvimento e de produção do eletroportátil e muitas vezes a área de design também auxilia na comunicação para que não aconteça ruído que possa interferir no lançamento do novo produto. Nota-se importante que depois de um longo processo os usuários sejam surpreendidos pelo novo produto e que compreendam a necessidade para qual ele esta suprindo, que seja acessível, e que ainda consigam enxergar credibilidade e tenham apelo emocional pela marca.

Segundo a Equipe de Design e Marketing da Cadence, chegada a data de lançamento dos produtos as amostras foram exibidas no Stand da Cadence na feira Eletrolar de 2015. A linha surpreendeu ao inovar nas cores, os produtos despertaram a atenção dos clientes e visitantes, que surpreenderam-se com a novidade. Destaca-se que esses 4 produtos já tinham suas versões em preto e branco, mas vistos em conjunto e com os mesmos padrões de cor, ganharam um apelo emocional muito maior no ponto de venda, o que fez com que até os clientes mais conservadores apostassem na tendência colors. Aos poucos os produtos foram entrando nas lojas, mercados e posteriormente nas casas de seus usuários, trazendo uma nova experiência para as cozinhas.

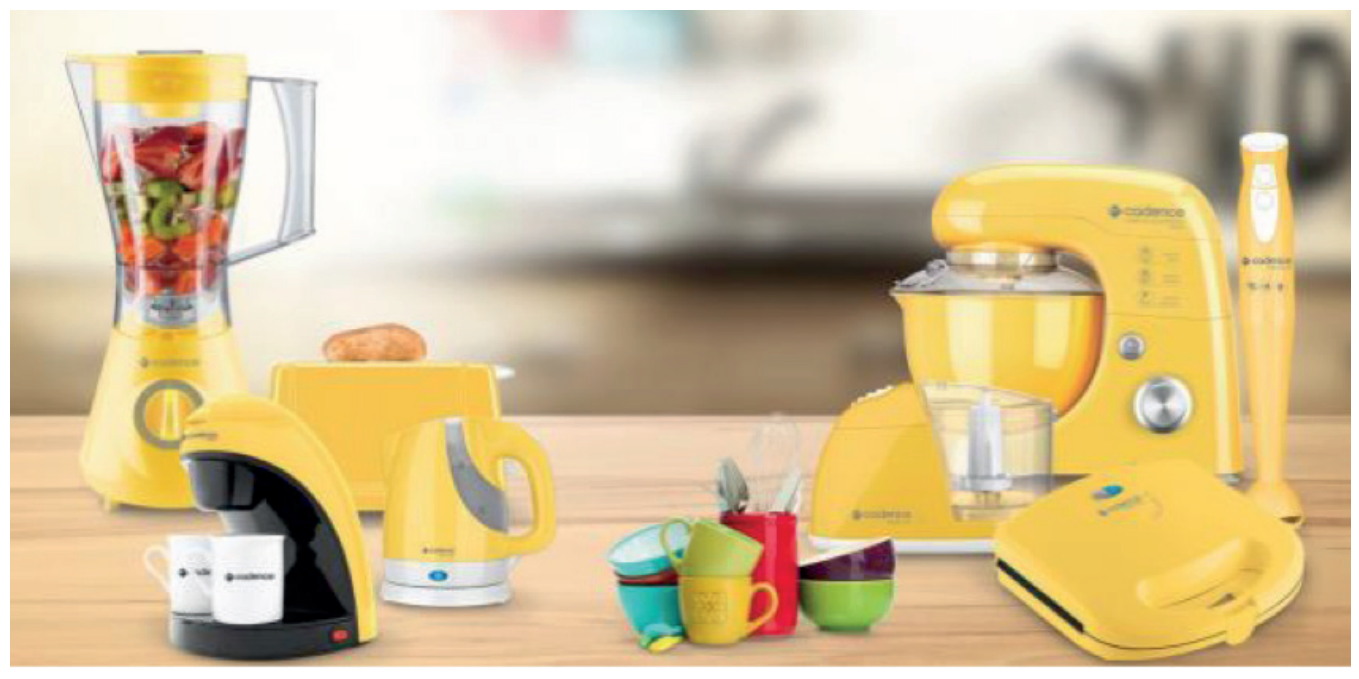

Figura 14: Linha Colors Cadence em 2014.

Fonte: Arquivos Cadence (2014) 
Devido à grande procura e a oportunidade de mercado, a marca complementou o seu portfólio com mais 4 produtos em 2015, formando então, uma linha com 8 produtos. Foram acrescentados o liquidificador com design exclusivo, o multiprocessador, o mixer e a torradeira, que somados aos 4 produtos já existentes, aumentaram o mix de produtos colors.

Além das cores e produtos que foram desenvolvidos, o posicionamento de preço, muito acessível ao consumidor, contribuiu também para a aquisição do novo produto. Com base em relatórios de vendas de plataformas e-commerce e varejistas, atualmente, grande parte do volume de vendas da marca Cadence cerca de $47,7 \%$, refere-se a linha Colors, sendo que o produto mais vendido, da marca é o liquidificador.

Cade ressaltar que todas as etapas aqui descritas são para reafirmar a essência do design praticada pela Cadence, em todo seu processo de inovação que é "traduzir observações em insights e estes em produtos e serviços para melhorar a vida das pessoas" (BROWN, 2010, p.46).

As contribuições que o design traz para o processo de inovação, está na incorporação do processo no modo de pensar da equipe, ou seja, pensar como um designer por meio de soluções eficazes aumenta a chance de sucesso das organizações industriais no desenvolvimento de novos produtos. De certa fora permite que todos os profissionais envolvidos no processo consigam pensar e adicional valor gerando novas perspectivas sobre determinado produto ou serviço. Nota-se que a implantação de uma cultura de inovação permite que todas as áreas estejam comprometidas e que todos possam ser coadjuvantes no processo de inovação e livres para pensar de forma criativa materealizando soluções inovadoras.

O lançamento desta linha, trouxe novos consumidores, que comportam-se como fãs e colecionadores da Linha Colors, onde o design aumentou o valor da experiência e o emocional do consumidor.

\section{CONSIDERAÇÕES FINAIS}

$O$ ato de inovar não significa inventar um produto totalmente novo. A inovação está nas pequenas coisas, e quando é bem aplicada, traz grande reconhecimento para a marca, que passa a ser cada vez mais sólida por trazer novidades ao mercado. Os produtos precisam ter diferenciais que despertem o sentimento e as emoções dos consumidores.

Segundo Baxter (2011), "quando existem dois produtos que se equivalem no valor funcional, a decisão de compra pode recair no valor simbólico". O design 
mexe com as pessoas e faz com que a compra aconteça. Enxergar as tendências no timing certo é criar o cenário perfeito para um lançamento consagrado.

O design aparece como uma nova forma de orientar as organizações e apresentar ferramentas e elementos que contribuam com o processo de inovação. Este artigo apresentou uma abordagem sobre o estudo de caso de uma Linha de Eletroportáteis desenvolvida pela empresa Cadence, onde o conhecimento e aplicação de métodos e técnicas de design contribuiram com o processo de inovação. Com a prática da inovação orientada pelo design, onde a busca por tendências e relações com foco na experiência do usuário fez com que a marca se consolida-se entre as mais vendidas do segmento gerando uma linha guia no mercado para este nicho.

Cabe ressaltar, que para um estudo mais profundado sobre o assunto e validar todas as relações que o design pode contribuir na organização, seria a proposta da implantação de um Programa de Design, onde todas as ações seriam orientadas num processo de gestão integrando todas as áreas e abrindo oportunidades de contribuição de centros de pesquisa e desenvolvimento voltados para inovação.

\section{REFERÊNCIAS}

BAXTER, Mike. Projeto de Produto: Guia prático para o design de novos produtos. 3. ed. São Paulo: Blucher, 2011.

BROWN, Tim. Design thinking: uma metodologia poderosa para decretar o fim das velhas ideias. Rio de Janeiro: Elsevier, 2010.

BRUNNER, Robert et al. Gestão estratéfica do design: Como um ótimo design fará as pessoas amarem a sua empresa. São Paulo: M.books Do Brasil Editora Ltda, 2010.

CLUR, Carlos. Venda de eletroportáteis deve avançar, mesmo com ano difícil. Disponível em: <http://www.dci.com.br/atos-legais/download/2015/4/ sqeoo20154520027.pdf>. Acesso em: 20 jun. 2015.

DESIGN COUNCIL. The Design Process. 2011. Disponível em: <http://www.designcouncil.org.uk/about-design/How-designers-work/The-design-process/>. Acesso em: outubro de 2014. 
DAY, G.S. A empresa orientada para o mercado. Porto Alegre: Bookman, 2001.

DRUCKER, P. F. Inovação e Espírito Empreendedor: Prática e Princípios. São Paulo: Pioneira, 1986.

DE MOZOTA, Brigitte Borja; KLÖPSCH, Cássia; DA COSTA, Filipe Campelo Xavier. Gestão do Design: Usando o Design para construir valor de marca e inovação corporativa. Porto Alegre: Bookman, 2011.

KOTLER, Philip; KELLER, Kevin L. Administração de marketing. 14. ed. São Paulo: Pearson, 2012.

Administração de marketing. 12. ed. São Paulo: Pearson Prentice Hall, 2006.

IBGE. Indicadores de março de 2015. Disponível em: <http://www.ibge.gov. br/home/estatistica/indicadores/industria/pimpf/br/pim-pf-br_201503comentarios.pdf >. Acesso em: 20 jun. 2015.

MARTINS, Conceição Garcia. Cozinhas, eletrodomésticos e modos de vida: implicações dos eletrodomésticos nas transformações de rotinas domésticas na cozinha, em residências de Florianópolis/SC. Disponível em: <http://www. utfpr.edu.br/curitiba/estrutura-universitaria/diretorias/dirppg/programas/ppgte/banco-teses/teses/ppgte_tese_13_2013.pdf>. Acesso em: 5 jun. 2015.

O NEGÓCIO DO VAREJO. Preço é decisivo na crise, mas consumidor quer manter as marcas habituais. Disponível em: http://onegociodovarejo.com. $\mathrm{br} /$ preco-e-decisivo-na-crise-mas-consumidor-quer-manter-as-marcas-habituais/>. Acesso em: 17 jul. 2015.

PRADO, Eduardo. Como será o seu eletrodoméstico na época da internet das coisas? Convergência Digital. Disponível em:<http://convergenciadigital. uol.com.br> Acesso em: 15 ago. 2015.

SOLOMON, Michael R. O comportamento do consumidor: comprando, possuindo e sendo. 9. ed. Porto Alegre: Bookman, 2011.

ZAMBARDA, Pedro. Internet das Coisas: entenda o conceito e o que muda 
com a tecnologia. Techtudo. Disponível em: <http://www.techtudo.com.br/ noticias/noticia/2014/08/internet-das-coisas-entenda-o-conceito-e-o-que-muda-com-tecnologia.html>. Acesso em: 19 ago. 2015.

Marcio Weber possui graduação em Engenharia Mecânica (UPF), mestrado em Engenharia de Produção (UFSM), doutorado em Engenharia Mecânica (UFRGS) e pós doutorado em Engenharia Mecânica pela Universidade Politécnica de Madrid (UPM / INSIA). É Professor do Curso de Engenharia Mecânica na Faculdade de Engenharia e Arquitetura da Universidade de Passo Fundo/RS e Coordenador do Mestrado Profissional em Projeto e Processos de Fabricação. É professor Coordenador do Projeto Baja UPF desde o ano de 2003. Tem experiência na área de Engenharia Mecânica, com ênfase em fundamentos gerais de projetos de máquinas, desenho técnico mecânico e projeto mecânico assistido por computador. Atua principalmente nas seguintes áreas: desenvolvimento de produtos, elementos finitos, análise dinâmica e impacto, ônibus e poltronas. Representante da Universidade de Passo Fundo como conselheiro titular no grupo Engenharia - modalidade Mecânica e Metalúrgica no Conselho Regional de Engenharia e Agronomia do Rio Grande do Sul - CREA-RS.

Carlos Davi Matiuzzi da Silva possui graduação em Design - ULBRA CARAZINHO (2006). Pós Graduação em Design Gráfico e Mídias - UPF, Mestrado em Design e Tecnologia, foi Coordenador e professor do Curso de Design da Universidade Luterana do Brasil - Campus Carazinho, onde também atuou nos cursos de Eng. de Produção e Administração .Foi Professor do Curso de Design da UNOESC-XXE, atuou também como professor na UNC Campus de Canoinhas, Coordenando o Núcleo de Design UNC - Canoinhas - SC, desenvolveu atividades de extensão no Curso de Design da UNOESC Campus de Xanxerê-SC como palestras e workshops. Atuou como professor nos cursos de Design da Univali Campus Balneario Camboriú e atualmente na Faculdade Energia em Florianópolis. Atua como docente nos seguintes temas: Materiais e Processos Gráficos, Design Editorial, Tipografia, Composição (Metodologia Visual), Design de Superfície (Processos Gráficos Aplicados em Superfícies Cerâmicas), Biônica, Ergonomia Cognitiva, Projeto de ambientes sob a interferência do design gráfico. Desenvolve volutariamente estudos sobre as manifestações do design gráfico decorrente dentro da história e sua influência na contemporaneidade e design conceitual de máquinas agrícolas. 